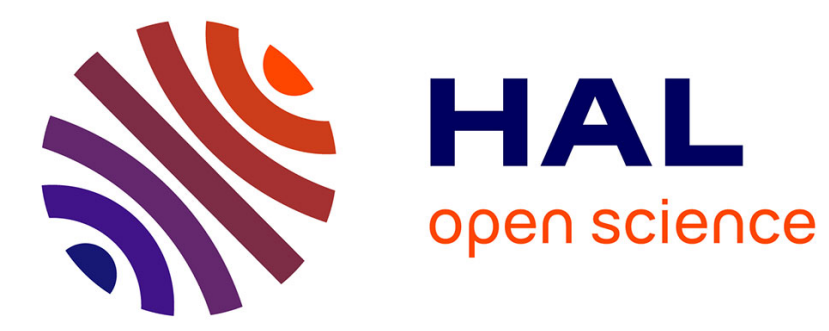

\title{
Coordination and Cooperation in Investment Timing with Externalities?
}

Etienne Billette de Villemeur, Richard Ruble, Bruno Versaevel

\section{To cite this version:}

Etienne Billette de Villemeur, Richard Ruble, Bruno Versaevel. Coordination and Cooperation in Investment Timing with Externalities?. 2011. halshs-00639471

\section{HAL Id: halshs-00639471 https://shs.hal.science/halshs-00639471}

Submitted on 9 Nov 2011

HAL is a multi-disciplinary open access archive for the deposit and dissemination of scientific research documents, whether they are published or not. The documents may come from teaching and research institutions in France or abroad, or from public or private research centers.
L'archive ouverte pluridisciplinaire HAL, est destinée au dépôt et à la diffusion de documents scientifiques de niveau recherche, publiés ou non, émanant des établissements d'enseignement et de recherche français ou étrangers, des laboratoires publics ou privés. 


\section{Coordination and Cooperation} in Investment Timing with Externalities

Etienne Billette de Villemeur, Richard Ruble, Bruno Versaevel

Octobre 2011 


\section{GATE Groupe d'Analyse et de Théorie Économique Lyon-St Étienne}

93, chemin des Mouilles 69130 Ecully - France

Tel. +33 (0)4 72866060

Fax $+33(0) 472866090$

6, rue Basse des Rives 42023 Saint-Etienne cedex 02 - France

Tel. +33 (0)4 77421960

Fax. $+33(0) 477421950$

Messagerie électronique / Email : gate@gate.cnrs.fr

Téléchargement / Download : http://www.gate.cnrs.fr - Publications / Working Papers 


\title{
Coordination and Cooperation in Investment Timing with Externalities*
}

\author{
Etienne Billette de Villemeur ${ }^{\dagger}$ Richard Ruble $^{\ddagger}$ Bruno Versaevel $^{\S}$
}

October 21, 2011

\begin{abstract}
We characterize sequential (preemption) and simultaneous (coordination) equilibria, as well as joint-value maximizing (cooperation) solutions, in a model of investment timing allowing for externalities in both flow profits and investment costs. For two ex-ante symmetric firms, either preemption or attrition occur depending on the size of the investment externality. Coordination is less likely with more discounting, as in a repeated game, and more likely with higher growth and volatility. Optimal cooperation involves either monopoly or duopoly investment, the latter being either symmetric or asymmetric. Finally, these characterizations are validated by applications to standard specifications of capacity accumulation and of R\&D investment. In the former setup, coordination is likelier if installed capacities and lumpy investments are both large. With $\mathrm{R} \& \mathrm{D}$ input choices, if investment synergies are large, coordination and cooperation result in the same outcomes.
\end{abstract}

JEL Classification: C73; D43; D92; L13

Keywords: Investment Timing; Real Options; Simultaneous Equilibrium; Joint-Value Maximization; Cooperation; Investment Externalities

* This paper was completed while Etienne Billette de Villemeur was visiting the University of Montreal whose hospitality is gratefully acknowledged. This version has benefited from comments at the 2010 conference of the European Association for Research in Industrial Organization, and at the 2011 International Conference on Real Options. We are particularly grateful to Lenos Trigeorgis for valuable comments. All remaining errors are ours.

${ }^{\dagger}$ EQUIPPE, Université de Lille, Villeneuve d'Ascq F-59655, France.

${ }^{\ddagger}$ Université de Lyon, Lyon F-69007, France; EMLYON Business School, Ecully F-69134 \& CNRS, GATE Lyon Saint Etienne, Ecully F-69130, France.

$\S$ Université de Lyon, Lyon F-69007, France; EMLYON Business School, Ecully F-69134 \& CNRS GATE Lyon Saint Etienne, Ecully F-69130, France. 


\section{Introduction}

Business circumstances in which firms in the same industry contemplate an investment in a growing market are prevalent. When demand is fluctuating and changes are uncertain, the investment timing impacts the expected value of their operations. In some cases, rival firms invest simultaneously. For example, two leaders in the vaccines sector, GlaxoSmithKline and Sanofi Pasteur MSD, a joint company of Sanofi Aventis and Merck, brought their competing human papilloma virus vaccines to market at roughly the same time. In some other circumstances, the same competitors invest sequentially. In the case of the dengue vaccine, Sanofi Pasteur seems to be a clear leader and GlaxoSmithKline a late entrant. ${ }^{1}$

Such interactions are best studied in continuous time, with preemption models, and, in a stochastic environment, with real option game models. ${ }^{2}$ Simultaneous investment can result either when firms non-cooperatively coordinate their decisions, or in some cases when they cooperate. Coordination has generally been modeled with the assumption that fixed costs are constant and stationary. A specificity of our paper is to focus on two kinds of externalities, profit externalities and investment externalities. The former are well-known in real option games, as one firm's investment generally impacts the flow profit of others. The latter are less often emphasized, but allow the model to encompass cases where fixed costs are affected by economies of scale in input production, location effects, or learning, to mention just a few. With respect to cooperation, to our knowledge very few papers model this behavioral assumption. Another contribution of this paper is to relate our general results to known industrial organization models by specifying the structure underlying what are usually taken to be reduced form flow profits.

More specifically, we construct a model which allows for the flow profit of a firm to be either reduced or enhanced by the competitor's investment, and where the relative investment cost of ex-ante symmetric firms depends on their sequence of moves, and thus is endogenous. This is complementary to several real option papers in the recent literature. In Hoppe [14] and in Huisman, Kort, and Thijssen [18], the state of the project in which firms invest is unknown ex-

\footnotetext{
${ }^{1}$ As for the human papilloma virus vaccines, "Gardasil by Merck has just been approved by the FDA [Federal Drug Administration] (June 2006) to prevent cervical cancer [...]; Cervarix by GlaxoSmithKline will be filed in 2006 for similar indications to those of Gardasil" (source: "Vaccines: growth boosters", Exane BNP Paribas Equity Research Report, June 2006, available at http://www.bionest.com/). For more on Sanofi Pasteur early investment in "a massive new manufacturing plant" for the production of a new vaccine against the dengue fever, see Carroll, J., 2009, "Sanofi breaks ground on $\$ 477 \mathrm{M}$ vax plant" (available at http://www.fiercevaccines.com).

${ }^{2}$ For recent surveys of game theoretic real options models, see Chevalier-Roignant, Flath, Huchzermeier, and Trigeorgis [7], Azevedo and Paxson [2], and Boyer, Gravel, and Lasserre [5].
} 
ante by both firms. There is a second-mover advantage, as the first investor informs the other firm whether the state of the project is low or high, though investment costs are symmetric. In Hoppe [14] the firms possibly already compete in the pre-investment period, in Huisman, Kort, and Thijssen [18] the market is new, and in both papers the first investor receives a higher flow profit. In Kort and Pawlina [20], the costs of exercising the investment option are assumed to differ across the two firms, and the effect of the magnitude of the ex-ante cost asymmetry on the nature of equilibrium is characterized. When the two firms have invested, their flow profits are symmetric.

In our model, the rank in the investment sequence determines the relative cost. The first investor can incur a lower investment cost, which can reflect a location effect (say, there is one best place for the investment). Alternatively, the second investor may benefit from a reduced cost, as would arise if there is a form of learning or experience effect pertaining to the investment process. The model specifications also capture situations in which a simultaneous investment has an impact - which can be either negative or positive - on investment costs, as occurs in case of congestion or synergies in the provision of a key input. Depending on the level of flow profits, which can capture cases of negative or positive product market externalities among competitors, the market can be new, or firms can be active before any investment has occurred.

In this general framework, our main objective is to provide a thorough characterization of sequential ("preemption") and simultaneous ("coordination") non-cooperative equilibria. We find that both preemption and attrition may occur, depending on the nature of investment externalities. A sequential (preemption) investment equilibrium occurs if the investment externality is negative, or not too positive. Otherwise the firms play a game of attrition. We provide a condition characterizing a simultaneous equilibrium, which we refer to as coordination. One key finding is that more discounting reduces the likelihood of coordination, a result that mirrors tacit collusion in a repeated game (supergame) context. Absent investment externalities, less interdependence between firms raises the likelihood of coordination.

Assuming that the requisite contracts are feasible, we also characterize a cooperative investment equilibrium, in which firms jointly maximize industry value. When the cost of being second is relatively high, optimal cooperation involves either symmetric duopoly investment, asymmetric duopoly investment, or a single monopoly investment, depending on structural conditions we fully describe.

Finally, we provide some applications of these results. We do this for both capacity choice by Cournot duopolists, and investment in demand-enhancing R\&D. In the examples we study, 
larger installed capacities ("footholds") and greater investment increments increase the likelihood of coordination, and greater spillovers and congestion effects in the production of R\&D increase the likelihood that cooperating firms stagger their investments.

The remainder of the paper is organized as follows. In Section 2, we construct the model, introduce the terminology, and describe the payoff functions. In Section 3, we characterize the relative investment costs for which a sequential (preemption) equilibrium exists. In Section 4, we derive a necessary and sufficient condition for the existence of a simultaneous (coordination) investment equilibrium, and discuss several corollaries. In Section 5 we study investment timing when firms cooperate in order to maximize industry value. In Section 6 we use our results to characterize simultaneous (coordination) equilibria in two model specifications, as adapted from the literature, that relate to capacity expansion and R\&D investment.

\section{The Model}

The assumptions, most of which are standard, are described in the first part of this section. Because the paper focuses on the link between specific externalities and the nature of equilibrium, the relevant terminology for the remainder of the paper is then described. Finally, we outline a set of payoff functions, which are standard for this kind of model and useful to the analysis that follows.

\subsection{Assumptions}

Flow profits are of the form $Y_{t} \pi_{i j}$, with $i, j \in\{0,1\}$. The multiplicative shock $Y_{t}$ is taken to follow a geometric Brownian motion $d Y_{t}=\alpha Y_{t} d t+\sigma Y_{t} d Z_{t}$, with $Y_{0}>0, \alpha>0$ (growth rate), $\sigma>0$ (volatility), and where $\left(Z_{t}\right)_{t \geq 0}$ is a standard Wiener process. For example, this shock may be thought of as a measure of market size that evolves stochastically over time. The value of the multiplicative shock at the current date is hereafter denoted by $y$. The positive initial state $Y_{0}$ is assumed to be lower than all positive thresholds we consider below. For the equation of motion to describe a market in expansion, it is assumed that $\alpha>\frac{\sigma^{2}}{2}{ }^{3}$ The interest rate, common to both firms, is $r$. To rule out degenerate solutions, it is assumed that $0<\alpha<r$. ${ }^{4}$

There are two risk-neutral firms which are ex-ante symmetric. The time invariant component of flow profit, $\pi_{i j}$, depends on the previous and current investment decisions of both firms. When

\footnotetext{
${ }^{3}$ The geometric brownian motion is derived from $Y_{t}=Y_{0} \exp \left[\left(\alpha-\frac{\sigma^{2}}{2}\right) t+\sigma Z_{t}\right]$ by using Itô's lemma.

${ }^{4}$ It can be proved easily that a firm increases value by waiting to invest forever if $r \leq \alpha$.
} 
appropriate, $\boldsymbol{\pi}$ is used to denote the vector $\left(\pi_{00}, \pi_{10}, \pi_{01}, \pi_{11}\right)$. Investment is a binary decision, and thus $i$ takes the value 1 if the firm has invested, and $j$ takes the value 1 if its rival has invested. ${ }^{5}$ If $\pi_{0 j}=0$ we have a new market case, otherwise firms are active in the pre-investment period. Investment is inherently discrete and of fixed size. For example, it may be thought of as a purchase of a manufacturing equipment, or as an R\&D expenditure. The assumption that investment is a binary decision means that we consider a single round of investment choices by the firms (see Boyer, Lasserre, and Moreaux [4] for a model where firms can invest in several "lumpy" capacity units). Investment is assumed to be desirable, that is $\pi_{1 i}>\pi_{0 i}, i \in\{0,1\}$. A second assumption regarding flow profit that is made throughout the paper is that $\pi_{10}>\pi_{01}$, that is a firm benefits more from its own investment than from its rival's.

Investment is costly, and the cost of investment may depend on previous and current investment decisions. If a single firm is the first to invest, this cost is denoted by $I_{L}$. If one firm has already invested, the cost to the second firm is denoted by $I_{F}$. Finally, if both firms invest simultaneously, this cost is denoted by $I_{S}$. Thus, a cost asymmetry may arise even though the two firms are identical ex-ante. ${ }^{6}$ Allowing $I_{L} \neq I_{F} \neq I_{S}$, with $I_{F}, I_{L}, I_{S}>0$, and no restriction in the ranking of the three cost levels, generalizes the analysis of some existing models (see the discussion on the terminology used in the paper below), and complements approaches in which flow profits depend on the entry sequence (such as in Mason and Weeds [24]). When appropriate, I is used to denote the vector $\left(I_{F}, I_{L}, I_{S}\right)$. In the analysis, the ratios of investment costs play an important role, and it is useful to define the following magnitudes: $\zeta_{F} \equiv \frac{I_{F}}{I_{L}}$ and $\zeta_{S} \equiv \frac{I_{S}}{I_{L}}$.

\subsection{Terminology}

The focus of this paper is the (non-cooperative) coordination equilibria and cooperative strategies in investment timing. These outcomes are to be understood with reference to a (non-cooperative) preemption equilibrium, where firms invest sequentially as a result of a race to be the first investor, and which dissipates monopoly rents. Firms deciding investment thresholds strategically may opt for an equilibrium that differs from preemption in at least two ways. First, in a coordination equilibrium, firms invest simultaneously. The choice of a sequential or simultaneous equilibrium solution may then be construed as a case of a coordination game. Second, the term cooperation

\footnotetext{
${ }^{5}$ We restrict $\pi_{11}$ to be independent of the sequence of investment decisions. For an alternative specification which allows for a persistent first-mover advantage, see Mason and Weeds [24] .

${ }^{6}$ A complementary work is Kort and Pawlina [20], which studies the effect of ex-ante fixed cost asymmetry on the nature of equilibrium.
} 
refers to a framework in which firms may make binding agreements and maximize industry profit (this terminology is discussed in Azevedo and Paxson [2]).

The following specific terminology is used in the rest of the paper. ${ }^{7}$

Investment is said to be jointly undesirable if $\pi_{11} \leq \pi_{00}$, and jointly desirable if $\pi_{11}>\pi_{00}$. This characteristic is key to determining the qualitative nature of coordination equilibrium, that is whether firms jointly abstain from ever investing, or jointly delay investing for the same finite amount of time. Either possibility may arise. For example, if investment involves an advertising campaign, negative advertising may decrease market size $\left(\pi_{11} \leq \pi_{00}\right)$, whereas preferenceenhancing advertising may increase it $\left(\pi_{11}>\pi_{00}\right)$.

Investment involves a (weakly) negative profit externality if $\pi_{i 1} \leq \pi_{i 0}$, and a positive profit externality otherwise, with $i \in\{0,1\}$. Note that since investment is taken to be individually desirable, if it is jointly undesirable, then there must be a negative direct externality (that is, $\pi_{00} \geq \pi_{11}$ and $\pi_{1 j}>\pi_{0 j}$ together imply $\left.\pi_{i 1}<\pi_{i 0}, i, j \in\{0,1\}\right)$. Negative profit externalities seem natural in situations such as capacity investment, whereas positive profit externalities may be thought of as arising if investment is in $\mathrm{R} \& \mathrm{D}$, when there is a large enough technological spillover. Note that we assume that $\pi_{10} \leq(<) \pi_{11}$ if and only if $\pi_{00} \leq(<) \pi_{01}$, so the direction of profit externalities is consistent.

Investment involves a (weakly) negative investment externality if $\zeta_{i} \geq 1$, and a positive investment externality otherwise, with $i \in\{F, S\}$. When necessary we refer to $\zeta_{S}$ as a measure of simultaneous investment externality. Investment externalities may arise in one of two ways. A firm's investment decision may raise or lower the cost of the next firm that invests. For example, the former $\left(\zeta_{F}>1\right)$ would arise if firms compete for some key resource, such as location, whereas the latter $\left(\zeta_{F}<1\right)$ would arise if there is a form of learning or experience effect pertaining to the investment process. A similar learning phenomenon arises in Hoppe [14] and Huisman, Kort, and Thijssen [18]. Alternatively, capacity may be resold from the first firm to the second (Li and Sick [22]), or an input supplier might practice price discrimination (Billette de Villemeur, Ruble, and Versaevel [3]). A second way in which investment externalities may arise is if joint investment has an impact on investment cost. This can happen either because there is a congestion in the provision of a key input (negative investment externality, $\zeta_{S}>1$ ), or a synergy if an important network externality arises when the firms enter the market together (positive investment externality, $\left.\zeta_{S}<1\right)$.

\footnotetext{
${ }^{7}$ Comparing with the expressions for firm payoffs given in the next section (expressions (2), (3), and (4)), the externalities described here concern the levels and slopes of some of the payoff terms.
} 


\subsection{Payoffs}

An equilibrium of the investment timing game involves a triplet of investment triggers chosen by the firms, which is denoted as $\left(y_{P}, y_{F}^{*}, y_{S}^{*}\right)$. The latter two triggers result from a well-studied optimization problem (see Dixit and Pindyck [9]), and have the following expressions

$$
y_{F}^{*}=\frac{\beta}{\beta-1} \frac{r-\alpha}{\pi_{11}-\pi_{01}} I_{F}, \quad y_{S}^{*}=\left\{\begin{array}{lc}
\frac{\beta}{\beta-1} \frac{r-\alpha}{\pi_{11}-\pi_{00}} I_{S}, & \pi_{11}>\pi_{00} \\
\infty, & \pi_{11} \leq \pi_{00}
\end{array},\right.
$$

where $\beta \equiv \frac{1}{2}-\frac{\alpha}{\sigma^{2}}+\sqrt{\left(\frac{\alpha}{\sigma^{2}}-\frac{1}{2}\right)^{2}+\frac{2 r}{\sigma^{2}}}$ is a standard expression in real option models. ${ }^{8}$ The sign of $\pi_{11}-\pi_{00}$ is key to determining the nature of the simultaneous equilibrium: when this expression is strictly positive, firms jointly delay investing until a finite threshold is reached. When it is negative however, in a simultaneous equilibrium, firms jointly abstain from ever investing.

Up to the relaxation of the constraint that investment cost is invariant, the investment timing game closely follows the analyses of Grenadier [12], Mason and Weeds [24], Boyer, Lasserre, and Moreaux [4]. The derivation of the preemption threshold and the characterization of equilibrium involve the following firm payoffs.

The value of a firm that invests immediately, when the current value of the multiplicative shock is $y$, is

$$
L(y)=\left\{\begin{array}{ll}
\frac{\pi_{10}}{r-\alpha} y-I_{L}+\left(\frac{y}{y_{F}^{*}}\right)^{\beta} \frac{\pi_{11}-\pi_{10}}{r-\alpha} y_{F}^{*}, & y \leq y_{F}^{*} \\
\frac{\pi_{11}}{r-\alpha} y-I_{S}, & y>y_{F}^{*}
\end{array},\right.
$$

where $L$ is used to refer to the fact that the firm is the leader in the market with respect to investment timing. Note that after $y_{F}^{*}$ is reached, one firm's investment immediately triggers the second's, so that investment is effectively simultaneous and the investment cost is $I_{S}$.

The value of a firm that invests as a follower when the multiplicative shock reaches the threshold $y_{F}^{*}$, provided that the current value of the multiplicative shock is $y$, and provided that the rival firm invests immediately at $y$, is

$$
F^{*}(y)=\left\{\begin{array}{ll}
\frac{\pi_{01}}{r-\alpha} y+\left(\frac{y}{y_{F}^{*}}\right)^{\beta}\left(\frac{\pi_{11}-\pi_{01}}{r-\alpha} y_{F}^{*}-I_{F}\right), & y \leq y_{F}^{*} \\
\frac{\pi_{11}}{r-\alpha} y-I_{S}, & y>y_{F}^{*}
\end{array},\right.
$$

where $F^{*}$ is used analogously to refer to the fact that the firm invests as a follower, and also to the fact that the investment threshold $y_{F}^{*}$ results from an optimization.

\footnotetext{
${ }^{8}$ In the certainty case, that is for $\sigma=0$, we have $\beta=\frac{r}{\alpha}$ and $\left(\frac{y}{y_{i}}\right)^{\beta}=e^{-r\left(t_{i}-t\right)}$, the continuous time discounting term.
} 
The value of a firm that invests when the multiplicative shock reaches the threshold $y_{S}^{*}$, provided that the current value of the multiplicative shock is $y$, and provided that the rival firm also invests only when the multiplicative shock reaches the threshold $y_{S}^{*}$, is

$$
S^{*}(y)= \begin{cases}\frac{\pi_{00}}{r-\alpha} y+\left(\frac{y}{y_{S}^{*}}\right)^{\beta}\left(\frac{\pi_{11}-\pi_{00}}{r-\alpha} y_{S}^{*}-I_{S}\right), & y \leq y_{S}^{*} \\ \frac{\pi_{11}}{r-\alpha} y-I_{S}, & y>y_{S}^{*}\end{cases}
$$

where $S^{*}$ is used to denote the fact that this payoff reflects simultaneous investment by the two firms, at a threshold $y_{S}^{*}$ that results from a straightforward optimization.

\section{Sequential Investment (Preemption) Equilibrium}

One focus of this paper is simultaneous investment and the coordination problem it may generate. A necessary condition for a coordination problem to arise is that there be another equilibrium solution, namely a sequential investment equilibrium. Since in our model player roles are endogenous, the sequential investment equilibrium we consider has the nature of a preemption equilibrium. In a preemption equilibrium, firms invest sequentially, either firm may be the leader with equiprobability, and the race to be first dissipates the rents that accrue to the first investor. A preemption equilibrium is characterized by the triggers $\left\{y_{P}, y_{F}^{*}\right\}$, with $y_{P}<y_{F}^{*}$, which denote the investment thresholds for the leader and follower. ${ }^{9}$ The preemption trigger $y_{P}$ is determined by the "rent equalization" condition $L\left(y_{P}\right)=F^{*}\left(y_{P}\right)$, i.e. firms are indifferent between investing as a leader at $y_{P}$ and investing as a follower at $y_{F}^{*}$ when the leader invests at $y_{P}$.

The existence of the preemption equilibrium when investment costs are invariant $\left(\zeta_{F}=1\right)$ is well-established, and the same reasoning establishes the existence of a preemption equilibrium with asymmetric firm-specific investment costs. ${ }^{10}$ With investment externalities, which is a source of investment cost asymmetry, the same argument applies.

Proposition 1 in this section characterizes the relative investment costs for which a preemption equilibrium exists. Essentially, preemption arises whenever the investment externality is negative, or when the investment externality is not too positive and profit externalities are negative. This is to be expected as a negative investment externality means that the first firm has a lower investment cost, and negative profit externalities induce preemption by reducing the attractiveness of the joint

\footnotetext{
${ }^{9}$ This is a simplification. See Fudenberg and Tirole [11], Huisman et al. [17], and Boyer et al. [4] for precise descriptions of the strategies underlying the preemption equilibrium.

${ }^{10}$ See Kort and Pawlina [20].
} 
investment phase. Otherwise, the investment game is a war of attrition, a case of independent interest but which is beyond the scope of this paper. ${ }^{11}$

For what follows, provided $z=\frac{\pi_{11}-\pi_{01}}{\pi_{10}-\pi_{01}} \leq \frac{\beta}{\beta-1}$, define the threshold

$$
\zeta_{P}(z, \beta) \equiv z[\beta-(\beta-1) z]^{\frac{1}{\beta-1}} .
$$

This expression appears as a lower bound on relative investment cost in Proposition 1. The following lemma describes the relevant behavior of $\zeta_{P}(z, \beta)$.

Lemma 1 For $\pi_{11}<\pi_{10}, \frac{\partial \zeta_{P}}{\partial z}(z, \beta)>0, \frac{\partial \zeta_{P}}{\partial \beta}(z, \beta)<0$ and $\zeta_{P}(z, \beta) \in(0,1]$.

Proof: See Appendix A.1

In what follows, we denote $\zeta_{P}(z, \beta)$ simply by $\zeta_{P}$. The conditions on $\zeta_{F}$ for a preemption equilibrium to exist can now be described.

Proposition 1 A sequential (preemption) equilibrium exists whenever $\zeta_{F}$ is sufficiently large:

(i) when profit externalities are non-negative $\left(\pi_{11} \geq \pi_{10}\right)$, a preemption equilibrium exists if and only if investment externalities are negative $\left(\zeta_{F}>1\right)$;

(ii) when profit externalities are negative $\left(\pi_{11}<\pi_{10}\right)$, a preemption equilibrium exists if and only if investment externalities are not too positive $\left(\zeta_{F} \geq \zeta_{P}\right)$.

Otherwise, the investment game is a war of attrition.

Proof: See Appendix A.2

Thus, if profit externalities are positive so it is disadvantageous to be the sole firm in the market to have invested, preemption occurs if there is a negative investment externality that makes investing first inherently attractive. In addition, if profit externalities are negative so it is advantageous to be the only firm to have invested, the condition is slacker and preemption occurs even with a positive investment externality that is not too strong. If the positive investment externality is too strong, neither firm seeks to enter first, and the investment game is in the nature of a war of attrition.

Since the study of the attrition game at this level of generality is beyond the scope of this paper, throughout the remainder it is assumed that the conditions of Proposition 1 on the investment externality $\left(\zeta_{F}\right)$ hold, so a preemption equilibrium exists.

\footnotetext{
${ }^{11}$ In Huisman et al. [18], the nature of the timing game similarly reverts from preemption to war of attrition depending on the magnitude of a second-mover advantage due to learning.
} 


\section{Simultaneous (Coordination) Equilibrium}

In this section we develop a necessary and sufficient condition for the investment timing game to have a simultaneous equilibrium, in which firms, instead of investing sequentially in a preemption equilibrium, both invest at the same trigger $y_{S}^{*}$, which may be infinite. ${ }^{12}$ We refer to this case as coordination. ${ }^{13}$

Unlike sequential (preemption) equilibrium in the previous section, in the presence of both investment and profit externalities, the simultaneous equilibrium may not be fully characterized. The main proposition therefore involves restrictions on the space of admissible parameters. In certain subcases that are given afterwards, a full characterization may be obtained.

To begin, define the following function:

$$
\widehat{f}(y) \equiv-\frac{\pi_{10}-\pi_{00}}{r-\alpha} y+I_{L}+\left(\frac{y}{y_{S}^{*}}\right)^{\beta} \frac{I_{S}}{\beta-1}+\left(\frac{y}{y_{F}^{*}}\right)^{\beta} \frac{\pi_{10}-\pi_{11}}{r-\alpha} y_{F}^{*} .
$$

Over the interval $\left[0, \min \left\{y_{F}^{*}, y_{S}^{*}\right\}\right]$, the expression in (6) corresponds to the difference $S^{*}-L$, that is to the incentive to invest simultaneously rather than immediately and unilaterally.

We assume:

Assumption (A) The parameter values $(\mathbf{I}, \boldsymbol{\pi}, \beta)$ are such that $\widehat{f}(y)$ is convex.

It can be shown that this assumption holds for all $\beta$ whenever $\pi_{10} \geq \pi_{11}$ (non-positive profit externalities). Otherwise (positive profit externalities), it requires that joint investment be desirable $\left(\pi_{11}>\pi_{00}\right)$ and then holds for instance for $\beta \approx 1$.

Next, define $y_{L}^{*} \equiv \frac{\beta}{\beta-1} \frac{r-\alpha}{\pi_{10}-\pi_{00}} I_{L}$. The trigger $y_{L}^{*}$ is the optimal investment threshold for a leader, if the sequence of investments is exogenously determined.

Assumption (B) The parameter values $(\mathbf{I}, \boldsymbol{\pi})$ are such that $y_{L}^{*}<\min \left\{y_{F}^{*}, y_{S}^{*}\right\}$.

This second condition requires the investment and profit externalities to be such that a firm, if given the guarantee of being the first to invest, would effectively choose to do so unilaterally.

\footnotetext{
${ }^{12}$ There is generally not just one, but a continuum of simultaneous equilibrium solutions, one of which is Pareto superior to the others. We follow convention in assuming that it is this latter solution which is chosen by rational players, and refer to it as "the" simultaneous equilibrium solution.

${ }^{13}$ In a framework where firms can restrict total production by non-cooperatively both postponing investment in capacity units, Boyer, Lasserre, and Moreaux [4] refer to simultaneous equilibrium as a case of "tacit collusion". We use the term "coordination" since in our model investments do not necessarily relate to production capacities, so that a departure from preemption equilibrium does not have the same anti-competitive character.
} 
As a benchmark, for $\zeta_{F}=\zeta_{S}=1$, Assumption $(B)$ requires that profit externalities be nonpositive (therefore in this case it implies Assumption $(A)$ ) and that flow profits be submodular $\left(\pi_{00}+\pi_{11} \leq \pi_{10}+\pi_{01}\right)$.

Proposition 2 Suppose Assumption (A) holds and consider the condition: ${ }^{14}$

$$
\beta\left(\frac{y_{F}^{*}}{y^{*}}-\zeta_{F}\right)\left(\frac{y_{L}^{*}}{y_{F}^{*}}\right)^{\beta}+\zeta_{S}\left(\frac{y_{L}^{*}}{y_{S}^{*}}\right)^{\beta} \geq 1
$$

$(\Rightarrow)$ if $(7)$ holds, a simultaneous equilibrium exists;

$(\Leftarrow)$ provided Assumption $(B)$ holds, then if a simultaneous equilibrium exists, (7) holds.

\section{Proof: See Appendix A.3}

It remains to check that, when a simultaneous (coordination) equilibrium exists, it can yield higher payoffs for both firms than the sequential (preemption) equilibrium. To do that, we introduce another value function (as compared with (2), (3), and (4) above). It describes the ex-ante expected value of a firm, at a market size $y \leq y_{P}$, when it anticipates that preemption occurs at $y_{P}$ and that it is equally likely to enter as a leader or as a follower at that threshold. ${ }^{15}$ Formally:

$$
V_{P}(y)=\frac{\pi_{00}}{r-\alpha} y+\left(\frac{y}{y_{P}}\right)^{\beta}\left(L\left(y_{P}\right)-\frac{\pi_{00}}{r-\alpha} y_{P}\right), \text { all } y \leq y_{P} .
$$

This payoff satisfies $V_{P}\left(y_{P}\right)=L\left(y_{P}\right)=F^{*}\left(y_{P}\right)$. When the market size is below the preemption trigger, it is the comparison of $S^{*}(y)$ with $V_{P}(y)$ that constitutes a valid criterion to assess whether the investment game has the features of a pure coordination game (i.e., whether the payoff from the simultaneous equilibrium is higher than the payoff under preemption, so that firms have an incentive to coordinate on the former).

Proposition 3 Suppose Assumptions (A) and (B) are satisfied. Then $V_{P}(y)<S^{*}(y)$, all $y \in$ $\left[0, y_{S}^{*}\right]$, so that the simultaneous investment equilibrium dominates the premption equilibrium.

\footnotetext{
${ }^{14}$ In condition (7) we use $y^{*}=\arg \max _{y_{i} \in\left[0, y_{F}^{*}\right]}\left(\frac{y}{y_{i}}\right)^{\beta}\left(\frac{\pi_{10}-\pi_{01}}{r-\alpha} y_{i}-I_{L}\right)+\left(\frac{y}{y_{F}^{*}}\right)^{\beta} \frac{\pi_{11}-\pi_{10}}{r-\alpha} y_{F}^{*}$, so that $y^{*}=$ $\frac{\beta}{\beta-1} \frac{r-\alpha}{\pi_{10}-\pi_{01}} I_{L}$. This is the trigger that would be chosen by an "altruistic" leader that internalizes the effect of its entry on the rival's profit (without necessarily maximizing industry profit, on this see Proposition 5).

${ }^{15}$ If initial conditions are such that $Y_{0}>y_{P}$, other issues may be raised ("mistakes" may arise, see Huisman and Kort [16]).
} 


\section{Proof: See Appendix A.4}

As is common in this literature, it is assumed throughout that when several equilibria exist, firms achieve the Pareto superior equilibrium (see also footnote 12). Therefore, by Proposition 3 , Proposition 2 is taken to provide conditions for a simultaneous investment equilibrium to effectively arise.

As a direct consequence of the condition (7) in Proposition (2), we find:

Corollary 1 A simultaneous equilibrium can arise even in the new market case.

In the new market case there are no profits without investment $\left(\pi_{00}=\pi_{01}=0\right)$. Corollary 1 is noteworthy because in so-called standard real option game models without investment externalities, it is only in the existing market case $\left(\pi_{00} \pi_{01}>0\right)$ that simultaneous equilibrium arises (Boyer, Lasserre, Moreaux [4], Chevalier-Roignant and Trigeorgis [6]). In the present model, the two firms may find it profitable to coordinate their investments on the same threshold when a unilateral deviation from the simultaneous equilibrium is sufficiently handicapped by a high $I_{L}$ (positive investment externality). For example, suppose that $\pi_{00}=\pi_{01}=0$, and $\pi_{11}=\frac{1}{9}$, $\pi_{10}=\frac{1}{4}$, with $r-\alpha=1, \beta=2$, and $I_{F}=I_{S} \cdot{ }^{16}$ Assumption $(A)$ is satisfied because profit externalities are negative, and condition (7) in Proposition 2 is satisfied for all $\zeta_{F} \leq \frac{56}{81}$.

Another result follows directly from the fact that, whenever $y_{L}^{*}<\min \left\{y_{F}^{*}, y_{S}^{*}\right\}$, in the limit the expression on the left side of the inequality sign in the condition (7) of Proposition 2 approaches 0 when $\beta$ tends to infinity.

Corollary 2 Suppose Assumptions (A) and (B) are satisfied. Then for $\beta$ large enough there is preemption rather than simultaneous equilibrium.

The parameter $\beta$ is increasing in the risk-free rate $r$, and decreasing in the drift $\alpha$ and volatility $\sigma$. The effect of $\beta$ on the likelihood of simultaneous equilibrium, as described by Corollary 2 , is thus consistent with the results that emerge in supergame models of tacit collusion. We now explore this comparison further.

The condition for simultaneous equilibrium that is characterized in Proposition $2, S^{*}(y)-$ $L(y) \geq 0$, may be rewritten in an equivalent form that bears analogy to the supergame setting:

$$
\frac{\pi_{10}-\pi_{00}}{r-\alpha} y\left[1-\left(\frac{y}{y_{S}^{*}}\right)^{\beta-1}\right]-\left[I_{L}-\left(\frac{y}{y_{S}^{*}}\right)^{\beta-1} I_{S}\right] \leq \frac{\pi_{10}-\pi_{11}}{r-\alpha} y\left[\left(\frac{y}{y_{F}^{*}}\right)^{\beta-1}-\left(\frac{y}{y_{S}^{*}}\right)^{\beta-1}\right] .
$$

\footnotetext{
${ }^{16}$ The numerical values for flow profits are drawn from a capacity investment example developed in section 6.1, where firms compete à la Cournot.
} 
The left side of the inequality (9) is the unilateral incentive to deviate from the simultaneous equilibrium, provided that the rival firm's investment trigger remains at the simultaneous equilibrium level $y_{S}^{*}$. This incentive consists of the present value of the increase in profits that results from the monopoly investment phase, net of the opportunity cost of procuring the input unilaterally at the smaller market threshold $y$, rather than latter at $y_{S}^{*}$. The right side of the inequality (9) is due to the reaction of the second firm to the (instantaneously) observed deviation of its rival from the simultaneous equilibrium. Its interpretation depends on both profit and investment externalities.

To see that, suppose that $y_{F}^{*}<y_{S}^{*}$. Then, upon observing a deviation at any $y<y_{F}^{*}$, the second firm lowers its investment trigger from $y_{S}^{*}$ to $y_{F}^{*}$. If profit externalities are negative, this earlier investment gives rise to a "punishment" phase, as the accelerated second investment shortens the period during which the first firm earns monopoly investment profits. ${ }^{17}$ This punishment phase does not start immediately after detection, and its duration is finite since the second firm would have invested at the trigger $y_{S}^{*}$ anyway had no deviation occurred. Thus, although there is some similarity to the stability condition that arises in supergames, ${ }^{18}$ and the corresponding equilibrium payoffs (i.e., those that result from the choice to cooperate or defect, with the restricted strategy spaces $\left\{y_{S}^{*}, y_{P}\right\}$ and $\left\{p^{M}, p^{M}-\varepsilon\right\}$ for investment timing and repeated Bertrand duopoly, respectively) have the same structure, ${ }^{19}$ the underlying dynamics are different in the investment timing and supergame contexts.

The rest of the section examines two special cases of simultaneous equilibrium.

\footnotetext{
${ }^{17}$ If $y_{F}^{*} \geq y_{S}^{*}$, then the second firm's reaction to the observed deviation is to delay its investment, which constitutes a "punishment" with respect to monopoly investment if profit externalities are positive.

${ }^{18}$ Consider a standard supergame, with infinite horizon, and trigger strategies à la Friedman [10], so that Nash reversion occurs forever if a firm deviates in any given period. Letting $\left(\pi^{C}, \pi^{D}, \pi^{N}\right)$ denote the (collusion, deviation, Nash) profits in the repeated stage game, with $\delta=\frac{1}{1+r}$, then the condition for collusion sustainability is $\pi^{D}-\pi^{C} \leq \frac{\delta}{1-\delta}\left(\pi^{C}-\pi^{N}\right)$.

${ }^{19}$ Given a state $y<y_{P}$, in strategic form the static $2 \times 2$ meta game with the restricted strategy space $\left\{y_{P}, y_{S}^{*}\right\}$ is:

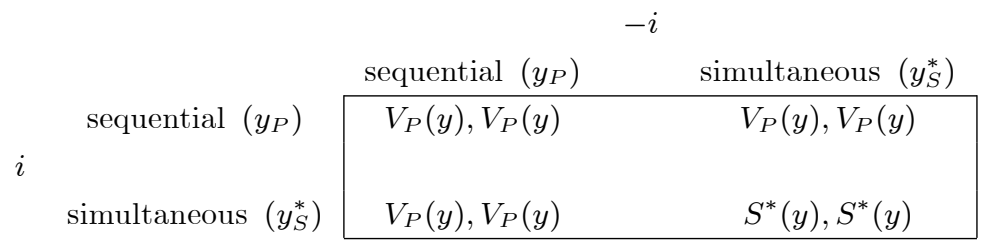

This payoff matrix has the same structure as the limit of the repeated game analog as period length (and detection lag) converge to zero. 


\subsection{No investment externalities $\left(\zeta_{F}=\zeta_{S}=1\right)$}

The case of no investment externalities is the one that corresponds most closely to what is termed the standard real options model (Azevedo and Paxson [2], and the derivation of the condition for coordination in this case can be found in Huisman [15]). Under the assumptions of Proposition 2 , flow profits must be submodular $\left(\pi_{00}+\pi_{11} \leq \pi_{10}+\pi_{01}\right)$ and profit externalities must be non-positive $\left(\pi_{i 1} \leq \pi_{i 0}, i \in\{0,1\}\right.$, and therefore Assumption $(A)$ holds). The condition for simultaneous equilibrium (7) then has the form:

$$
f(u, v, w ; \beta) \equiv \beta u v^{\beta}+w^{\beta} \geq 1,
$$

with $u \equiv \frac{\pi_{10}-\pi_{11}}{\pi_{11}-\pi_{01}}>0, v \equiv \frac{\pi_{11}-\pi_{01}}{\pi_{10}-\pi_{00}} \in(0,1]$ and $w \equiv \frac{\pi_{11}-\pi_{00}}{\pi_{10}-\pi_{00}} \in(0, v]$. This function is not monotonic in $\beta$, but it is bounded above and below by functions whose behavior is straightforward to study: $f(u, v, w ; \beta) \in\left[\beta u v^{\beta},(\beta u+1) v^{\beta}\right]$. This is represented in Figure 1 , taking $u=1$. The solid (higher) curve is the locus $\beta v^{\beta}=1$, which describes a sufficient condition for simultaneous equilibrium $\left(\beta v^{\beta} \geq 1\right)$; and the dash (lower) curve is the locus $(\beta+1) v^{\beta}=1$, which describes a necessary condition for simultaneous equilibrium $\left((\beta+1) v^{\beta} \geq 1\right)$.

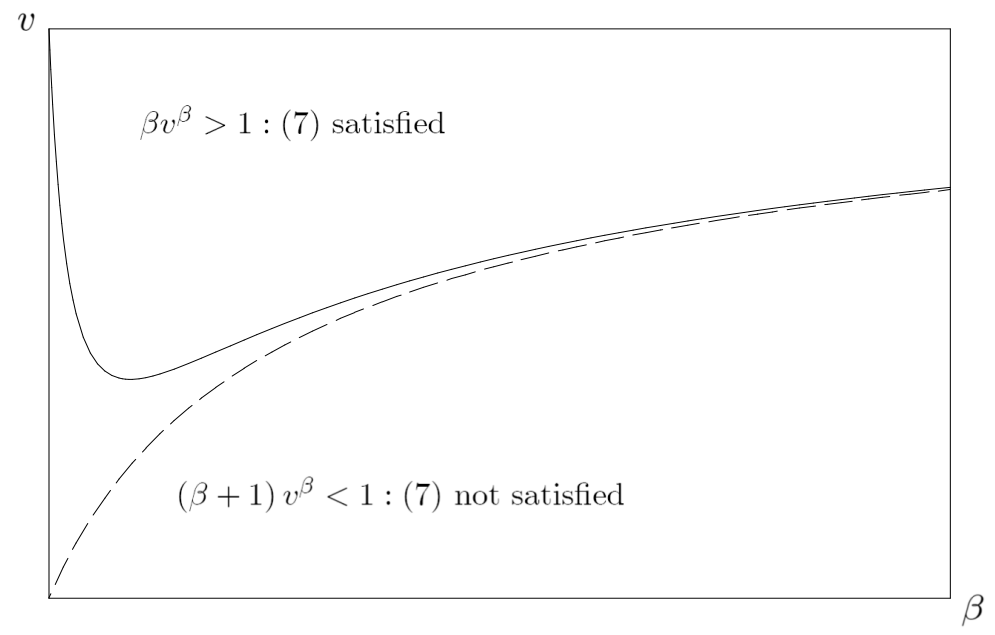

Figure 1: Necessary (dashed curve) and sufficient (solid curve) conditions on $\left(\beta, \frac{\pi_{11}-\pi_{01}}{\pi_{10}-\pi_{00}}\right)$ for simultaneous equilibrium (with no investment externalities, $\zeta_{F}=\zeta_{S}=1$ ).

Thus, without investment externalities, the lower the complementarity in flow profits (the "less submodular" flow profits are, as $v \equiv \frac{\pi_{11}-\pi_{01}}{\pi_{10}-\pi_{00}}$ converges to 1 from below), the more likely is 
simultaneous equilibrium. Put another way, simultaneous equilibrium is more likely when flow profits are less interdependent, i.e. when the impact of a firm's investment on its flow profit is unaffected by rival investment $\left(\pi_{11}-\pi_{01}\right.$ almost equal to $\left.\pi_{10}-\pi_{00}\right)$, and less likely otherwise.

By continuity, it is therefore possible to complement Corollary 2 as follows.

Corollary 3 Suppose Assumptions $(A)$ and $(B)$ are satisfied. Then, if profit externalities do not reflect strong interdependence $\left(\pi_{11}+\pi_{00} \approx \pi_{10}+\pi_{01}\right)$ and investment externalities are small enough $\left(\zeta_{P}, \zeta_{S} \approx 1\right)$, a simultaneous equilibrium arises.

\subsection{Joint investment not desirable $\left(\pi_{00} \geq \pi_{11}\right)$}

In this subsection we examine the case in which joint investment is not desirable. In this case, in a simultaneous equilibrium both firms refrain from ever investing $\left(y_{S}^{*}=\infty\right)$, so we refer to this the infinite delay case. Because investment is individually desirable $\left(\pi_{1 j}>\pi_{0 j}\right)$, it follows that profit externalities are negative $\left(\pi_{i 0}>\pi_{i 1}, i \in\{0,1\}\right.$, and therefore Assumption $(A)$ holds). By Proposition 1, for a preemption equilibrium to exist, investment externalities must therefore satisfy $\zeta_{F} \geq \zeta_{P}$

In the infinite delay case, it is possible to fully characterize simultaneous equilibrium. This characterization is similar to Proposition 2, but is not a proper subcase because Assumption $(B)$ does not enter into the result. Moreover, it is informative to express the necessary and sufficient condition for simultaneous equilibrium (7) in a form that distinguishes the effect of investment externalities. To this end, we now introduce a threshold,

$$
\zeta_{S_{\infty}}(\boldsymbol{\pi}, \beta) \equiv \frac{\pi_{11}-\pi_{01}}{\pi_{10}-\pi_{00}}\left(\beta \frac{\pi_{10}-\pi_{11}}{\pi_{10}-\pi_{00}}\right)^{\frac{1}{\beta-1}} .
$$

This expression appears as an upper bound on relative investment cost $\left(\zeta_{F}\right)$ in Proposition 4 below. The following lemma describes the behavior of $\zeta_{S_{\infty}}(\boldsymbol{\pi}, \beta)$.

Lemma $2 \zeta_{P}<\zeta_{S_{\infty}}(\boldsymbol{\pi}, \beta), \zeta_{S_{\infty}}(\boldsymbol{\pi}, \beta) \in\left[\frac{\pi_{11}-\pi_{01}}{\pi_{10}-\pi_{00}}, \infty\right)$, and $\frac{\partial \zeta_{S_{\infty}}(\boldsymbol{\pi}, \beta)}{\partial \beta}<0$.

\section{Proof: See Appendix A.5}

In what follows, we denote $\zeta_{S_{\infty}}(\boldsymbol{\pi}, \beta)$ simply by $\zeta_{S_{\infty}}$. The conditions on $\zeta_{F}$ characterizing simultaneous equilibrium is: 
Proposition 4 Suppose that joint investment is not desirable $\left(\pi_{00} \geq \pi_{11}\right)$, and that a preemption equilibrium exists $\left(\zeta_{F} \geq \zeta_{P}\right)$. Then, a simultaneous equilibrium arises if and only if $\zeta_{F} \leq \zeta_{S_{\infty}}$.

Proof See Appendix A.6

Propositions 1 and 4 together describe the qualitative evolution of equilibrium as a function of the relative investment cost $\zeta_{F}$. There are three equilibrium regions. First, if the relative investment cost of the second firm is low $\left(0 \leq \zeta_{F}<\zeta_{P}\right)$, no firm wishes to enter first so there is no preemption, and only non-investment simultaneous equilibrium or attrition. Second, in an intermediate range of relative investment $\operatorname{cost}\left(\zeta_{P} \leq \zeta_{F} \leq \zeta_{S_{\infty}}\right)$, both preemption and simultaneous equilibria exist, with the simultaneous equilibirum dominating the sequential one. Third, if the relative investment cost of the second firm is sufficiently high $\left(\zeta_{S_{\infty}}<\zeta_{F}\right)$, only preemption (sequential investment) arises as an equilibrium. Thus, greater negative investment externalities increase the likelihood of preemption and reduce the likelihood of a simultaneous infinite delay equilibrium.

By a similar argument as in the previous section, here also Proposition 3 applies to show that a simultaneous equilibrium is Pareto optimal. Moreover, analogously to Corollary 2, applying Lemma 2 one obtains:

Corollary 4 If investment externalities are non-negative and flow profits are supermodular, then a simultaneous equilibrium arises for all $\beta$. Also, an increase in $\beta$ reduces the likelihood of simultaneous equilibrium. Finally, rent-shifting investment $\left(\pi_{00} \approx \pi_{11}\right)$ raises the likelihood of simultaneous equilibrium.

\section{Cooperation (with Asymmetric Investment Triggers)}

Papers on real options game generally assume non-cooperative behavior on the part of firms. ${ }^{20}$ This section studies investment timing with an alternative behavioral hypothesis, which is that firms choose triggers so as to maximize industry profit. If contracting options such side payments are allowed between parties, firms might choose to cooperate on the choice of asymmetric

\footnotetext{
${ }^{20}$ A notable exception is Weeds [29], where firms invest in uncertain R\&D projects, and can cooperate by adopting a joint-investment strategy, as if they were two R\&D units under common ownership. This is a new market model (pre-investment profits are zero) with negative profit externalities (successful innovation by one firm eliminates profits for its competitor), and there is no investment externality unless firms opt for R\&D cooperation.
} 
investment triggers. We refer to this framework as cooperation. ${ }^{21}$

Before an investment occurs each firm's flow profit is $\pi_{00}$, and in case of monopoly investment the average industry profit is $\bar{\pi} \equiv \frac{\pi_{10}+\pi_{01}}{2}$. The ex-ante industry value (where $J$ stands for "joint"), when the current value of the multiplicative shock is $y$, is

$$
J(y)=\left\{\begin{array}{ll}
2 \frac{\pi_{00}}{r-\alpha} y+\left(\frac{y}{y_{L}}\right)^{\beta}\left(\frac{2\left(\bar{\pi}-\pi_{00}\right)}{r-\alpha} y_{L}-I_{L}\right)+\left(\frac{y}{y_{F}}\right)^{\beta}\left(\frac{2\left(\pi_{11}-\bar{\pi}\right)}{r-\alpha} y_{F}-I_{F}\right), & y_{L}<y_{F} \\
2\left[\frac{\pi_{00}}{r-\alpha} y+\left(\frac{y}{y_{S}}\right)^{\beta}\left(\frac{\pi_{11}-\pi_{00}}{r-\alpha} y_{S}-I_{S}\right)\right] & y_{L}=y_{F}\left(\equiv y_{S}\right)
\end{array} .\right.
$$

Firms that cooperate will choose triggers that optimize the payoff (12), solving the problem $\max _{\left\{\left(y_{L}, y_{F}\right), y_{L} \leq y_{F}\right\}} J(y)$. This optimization problem is, in fact, the same as that of a monopoly firm, if it has the option to make not just one but two investments. The optimum need not be the symmetric triggers $\left(y_{S}^{*}, y_{S}^{*}\right)$ because the firms may collectively prefer to stagger their investments.

Provided that $\pi_{00}<\bar{\pi}$, define the trigger $y_{L}^{* *}=\frac{\beta}{\beta-1} \frac{r-\alpha}{2\left(\bar{\pi}-\pi_{00}\right)} I_{L}$, and provided that $\bar{\pi}<\pi_{11}$, define the trigger $y_{F}^{* *}=\frac{\beta}{\beta-1} \frac{r-\alpha}{2\left(\pi_{11}-\bar{\pi}\right)} I_{F}$. These triggers, when they exist, are well-defined in the interior of the domain of $J$, that is $\left\{\left(y_{L}, y_{F}\right) \in \mathbb{R}_{+}^{2}, y_{L}<y_{F}\right\}$, whenever $\zeta_{F}>\frac{\pi_{11}-\bar{\pi}}{\bar{\pi}-\pi_{00}}$. For example, if there are no investment externalities $\left(\zeta_{F}=1\right)$, this condition holds if flow profits are strictly submodular.

Proposition 5 Suppose that investment externalities are not too small $\left(\zeta_{F}>\frac{\pi_{11}-\bar{\pi}}{\bar{\pi}-\pi_{00}}\right)$ so the industry payoff $(J)$ has a well-defined maximum. ${ }^{22}$ Optimal cooperation involves either symmetric duopoly investment, asymmetric duopoly investment, or a single firm investment:

(i) when monopoly investment lowers industry profit $\left(\bar{\pi} \leq \pi_{00}\right)$, optimal cooperation involves symmetric investment triggers $\left(y_{S}^{*}, y_{S}^{*}\right)$, where $y_{S}^{*}$ is infinite if $\pi_{00} \geq \pi_{11}$;

(ii) when monopoly investment raises industry profit $\left(\bar{\pi}>\pi_{00}\right)$, optimal cooperation involves finite symmetric investment triggers $\left(y_{S}^{*}, y_{S}^{*}\right)$ if and only if

$$
0.5 \frac{I_{L}}{y_{L}^{* * \beta}}+\mathbf{1}_{\left\{\bar{\pi}<\pi_{11}\right\}} 0.5 \frac{I_{F}}{y_{F}^{* * \beta}}<\frac{I_{S}}{y_{S}^{* \beta}},
$$

and asymmetric investment triggers $\left(y_{L}^{* *}, y_{F}^{* *}\right)$ otherwise, where $y_{F}^{* *}$ is infinite if $\pi \geq \pi_{11}$.

Proof See Appendix A.7

\footnotetext{
${ }^{21}$ Here again we do not use the term "collusion" because explicit agreements on investment times do not clearly constitute an illegal practice in the same way as price-fixing agreements do.

${ }^{22}$ If $\zeta_{F}<\frac{\pi_{11}-\bar{\pi}}{\bar{\pi}-\pi_{00}}$ then $y_{F}^{* *}<y_{L}^{* *}$, and $J$ may have a downward jump at $\left(y_{L}^{* *}, y_{L}^{* *}\right)$ if $\zeta_{S}$ is large enough.
} 
Comparing Proposition 5 with Corollaries 2 and 3, the conditions for simultaneous equilibrium when firms act non-cooperatively are independent of the type of optimal solution they choose if they act cooperatively.

Corollary 5 The greater the (negative) simultaneous investment externality (the larger is $\zeta_{S}$ ), the more likely it is that optimal cooperation involves asymmetric investment. If joint investment is desirable $\left(\pi_{11}>\pi_{00}\right)$, then the larger is $\beta$, the less likely it is that optimal cooperation involves asymmetric investments.

Proof The first part follows directly from (13). To establish the second, note that in the limit, (13) requires $\frac{I_{S}}{y_{S}^{*}}<0.5 \min \left\{\frac{I_{L}}{y_{L}^{* *}}, \frac{I_{F}}{y_{F}^{* *}}\right\}$, i.e. $\pi_{11}-\pi_{00}<\min \left\{\bar{\pi}-\pi_{00}, \pi_{11}-\bar{\pi}\right\}$.

\section{Applications}

In the real option games literature, flow profits are generally not specified further than the reduced form $\boldsymbol{\pi}$. At the same time, compatibility between the simultaneous equilibrium conditions (condition (7) in Proposition 2 and condition (13) in Proposition 5) and economic fundamentals is not apparent at first glance. The examples of this section provide a comprehensive study of different natures of equilibria by specifying the economic model generating the flow profit. We focus on two structures that are associated with preemption games, namely capacity expansion and R\&D investment, which offer simple applications of the theoretical results we derived in the previous sections.

\subsection{Capacity Investment with Quantity Competition}

A canonical application of preemption is to capacity investment by duopolists. In a forthcoming paper, Boyer, Lasserre and Moreaux [4] study industry development with Cournot duopolists that acquire lumpy capacity units over time as inverse demand grows stochastically. Firms face an inverse market demand that is of the form $Y_{t} D\left(x_{1}+x_{2}\right)$, where $Y_{t}$ is a stochastic multiplicative shock and $x_{i}$ refers to firm output, have zero marginal production cost, and compete in quantity. Over time, firms engage in several rounds of lumpy capacity investment over an industry development "tree". We consider a subcase of their model in two respects. First, we assume that the ex-ante symmetric firms have sufficient installed capacity so that just a single investment round is necessary for them to reach the Cournot equilibrium output level. Second, inverse demand is here specified to be linear, $D\left(x_{1}+x_{2}\right)=1-x_{1}-x_{2}$. 
Let $k$ denote the existing capacity of each firm, which is assumed to be symmetric, and $\delta$ the (lumpy) increase in capacity that results from the acquisition of another unit of the specific input. Both firms are initially capacity constrained at $k$, so they earn $\pi_{00}=(1-2 k) k$, with $0 \leq k \leq 1 / 2$. Each firm can relax the constraint by investing in one additional unit of size $\delta>0 .^{23}$ The end of the investment game is near, in that a single round of investment remains. That is, $x^{c}-\delta \leq k<x^{c}$, where here $x^{c}=\frac{1}{3}$ denotes the unconstrained Cournot output level, so that $\pi_{11}=\frac{1}{9}$. Firms decide non-cooperatively (contracts are ruled out) and without commitment when to invest in an additional unit. There are no investment externalities, that is $\zeta_{F}=\zeta_{S}=1$.

In this framework, we seek conditions on the parameters $k$ and $\delta$ under which a simultaneous equilibrium arises (we leave cooperative equilibrium aside in this example). This allows us to partition the $(k, \delta)$ parameter space (see Figure 2). Even with simplifying assumptions (linear demand, no investment externalities, single capacity investment, no cooperation), a variety of equilibrium configurations emerges. Broadly, the likelihood of simultaneous (coordination) equilibrium increases with firms' initial installed capacity $k$, so coordination is "likelier when firms have footholds rather than toeholds", and is non-decreasing in the capacity increment $\delta$.

Note first that the parameter space is bounded by the constraint that firms are initially capacity constrained and that the end of the game is near. With the linear inverse demand, $x^{c}-\delta \leq k<x^{c}$ implies $k \in\left[0, \frac{1}{3}\right)$ and $\delta \geq \frac{1}{3}-k$. Next, if the investment increment is relatively small, a firm that invests independently in additional capacity, while its rival does not invest, may still be capacity constrained relatively to its Cournot best reply. Slightly abusing terminology, we refer to this situation as the capacity constrained case. With the linear inverse demand a firm's best response is a corner solution $x_{i}^{*}(k)=k+\delta$ (rather than the best-reply $x_{i}^{*}(k)=\frac{1-k}{2}$ ) if $\delta \leq \frac{1}{2}-\frac{3}{2} k$. Then, flow profits are $\pi_{10}=(k+\delta)(1-2 k-\delta)$ and $\pi_{01}=k(1-2 k-\delta)$ (rather than $\pi_{10}=\left(\frac{1-k}{2}\right)^{2}$ and $\pi_{01}=\frac{k(1-k)}{2}$ in the unconstrained case). The construction of Figure 2 thus runs as follows. Below the light solid line $\left(\delta=\frac{1}{3}-k\right)$, more than one investment round is necessary to attain the Cournot capacities, so we restrict attention to the points above that line. In the latter subspace, the light dashed line $\left(\delta=\frac{1}{2}-\frac{3}{2} k\right)$ partitions those parameter values for which firms are capacity constrained (below) in case of unilateral investment from those for which they are not (above).

Against this backdrop, the conditions for simultaneous equilibrium may be assessed. To do that, note first that, with $\zeta_{F}=\zeta_{S}=1$ the condition in $(7)$ simplifies to the form $\widetilde{f}(\beta) \equiv$ $\beta u v^{\beta}+\mathbf{1}_{\pi_{11}>\pi_{00}} w^{\beta} \geq 1$ where $u \equiv \frac{\pi_{10}-\pi_{11}}{\pi_{11}-\pi_{01}}, v \equiv \frac{\pi_{11}-\pi_{01}}{\pi_{10}-\pi_{00}}>0$, and $w \equiv \frac{\pi_{11}-\pi_{00}}{\pi_{10}-\pi_{00}} \leq v$. (The indicator

\footnotetext{
${ }^{23}$ This extends slightly the specifications in Boyer, Lasserre and Moreaux [4], where $\delta=1$.
} 
function is there to capture the specification that $\pi_{11} \leq \pi_{00}$ implies $y_{S}^{*}=\infty$, hence $\frac{y_{L}^{*}}{y_{S}^{*}}=0$ in (7).) The following lemma describes the behavior of $\tilde{f}$, independently of the specification of flow profit (and thus applies whether firms are capacity constrained or not).

Lemma 3 The function $\tilde{f}$ is quasiconcave, and $\tilde{f}(1) \geq 1$ with equality if and only if $\pi_{11} \geq \pi_{00}$.

Proof: See Appendix A.8

By Lemma 3, if $\pi_{11}<\pi_{00}$ we have $\tilde{f}(1)>1$, so that a simultaneous equilibrium exists over an interval of values $(1, \bar{\beta}]$, by continuity. Otherwise $\widetilde{f}(1)=1$, and a simultaneous equilibrium arises for some $\beta$ only if $\widetilde{f}^{\prime}(1) \geq 0$.

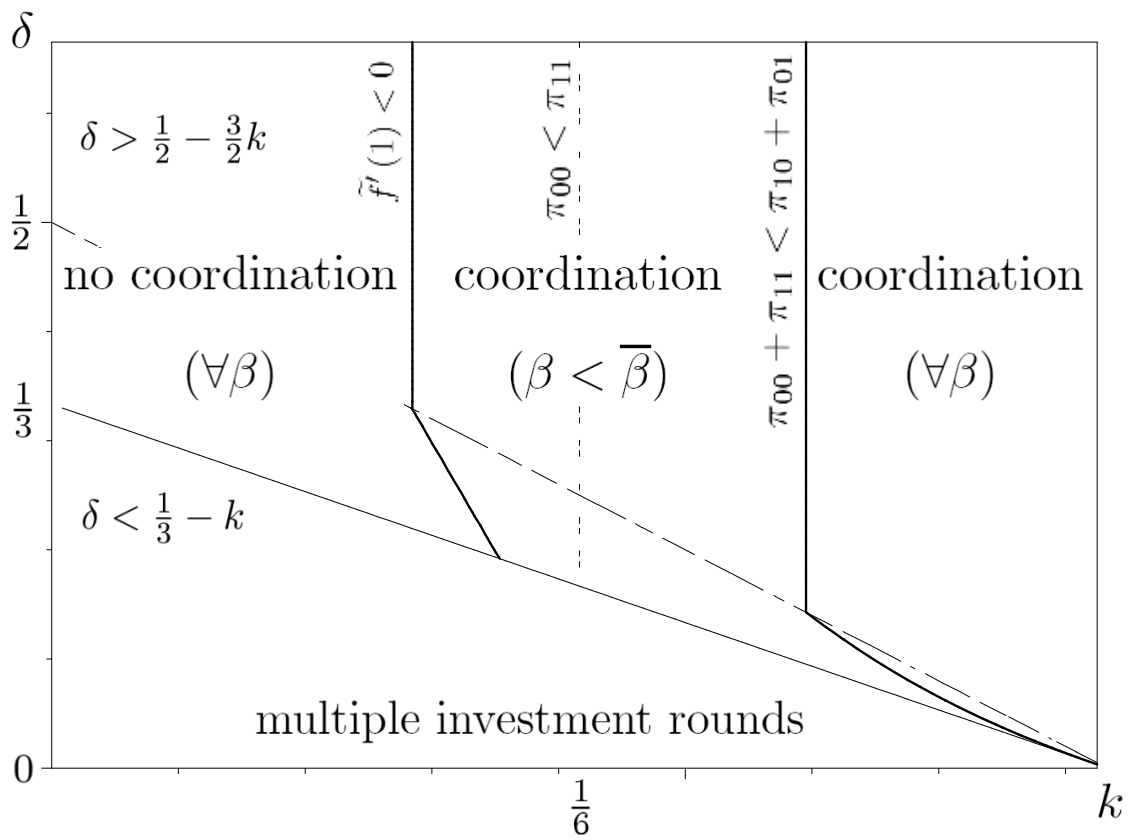

Figure 2: Simultaneous equilibrium/coordination in capacity investment with linear demand and no investment externality, given initial capacity $(k)$ and investment increment $(\delta)$.

Three additional frontiers can now be depicted in Figure 2. First, with the linear inverse demand specification, the dotted vertical line $k=\frac{1}{6}$ is the locus of points for which $\pi_{11}=\pi_{00}$. Joint investment is desirable $\left(\pi_{11}>\pi_{00}\right)$ only to the left of that frontier. Next, we graph two bold curves. The one to the left plots the values of $(k, \delta)$ for which $\widetilde{f}(1)=1$ and $\widetilde{f}^{\prime}(1)=0$. The 
other bold curve, to the right, separates out those values for which $\boldsymbol{\pi}$ is strictly submodular, i.e. $\pi_{00}+\pi_{11}<\pi_{01}+\pi_{10}$, (bottom and left) for which they are not (to the Northeast). Evaluating, flow profits are strictly supermodular if $k>\frac{5}{21}$ (not capacity constrained case) or $(1-2 k) k+$ $(2 k+\delta)(2 k+\delta-1)+\frac{1}{9}<0$ (capacity constrained case).

This leads to a partition of the parameter space into three subregions. In the middle region, both Assumptions $(A)$ and $(B)$ are verified, so that Proposition 2 applies directly. Indeed, as $\zeta_{F}=\zeta_{S}=1$, the negative profit externality, with implies that Assumption $(A)$ is verified for all parameter values, also implies that Assumption $(B)$ is verified if and only if $\boldsymbol{\pi}$ is submodular. ${ }^{24}$ In that case, the condition in (7) is satisfied so long as $\beta$ is "not too large", with an upper bound that increases with $k$. Moreover, the desirability of joint investment determines the nature the simultaneous equilibrium that may arise. To the left of $k=\frac{1}{6}$, in any simultaneous equilibrium firms invest at a finite trigger beyond the preemption triggers, whereas to the right firms abstain from ever investing.

Next, in the leftmost region, we have $\pi_{11}>\pi_{00}$ and $\widetilde{f}^{\prime}(1)<0$, and there is no simultaneous equilibrium for any value of $\beta$. Finally, in the rightmost region, all points are to the right of the joint desirability frontier, so $\pi_{11}>\pi_{00}$, and $\pi$ is supermodular. It follows from Corollary 4 that a simultaneous equilibrium exists for all $\beta$ in this region.

To summarize, a rich pattern of equilibria arises:

Proposition 6 Greater preexisting capacity $k$, as well as greater increments $\delta$ (if preexisting capacity is sufficiently large) increase the likelihood of simultaneous (coordination) equilibrium. When $k$ is low enough there is no simultaneous equilibrium for any $\delta$, as in the new market case.

A detailed welfare analysis is beyond the scope of the present paper but we can make the following observations. If preexisting capacities are low (for $k<1 / 6$ ), firms eventually invest and both reach the Cournot outcome in the product market more or less early, whether by means of a staggered or a joint investment. However, if preexisting capacities are high, in a simultaneous equilibrium firms might never invest and product market outcomes may be perennially less competitive than those of Cournot competition, and (because investment is lumpy) for some parameter values even strictly less competitive than the monopoly outcome (when $k \in[1 / 6,1 / 4$ ), for large enough $\delta$ ), even though no illegal collusion (in the sense of a price-fixing or market-sharing agreement) has occurred.

\footnotetext{
${ }^{24}$ More precisely, with $\zeta_{F}=\zeta_{S}=1$, the negative profit externality $\left(\pi_{10} \geq \pi_{11}\right)$ implies that $\frac{I_{S}}{I_{L}}=1 \geq \frac{\pi_{11}-\pi_{00}}{\pi_{10}-\pi_{00}}$, which is equivalent to $y_{L}^{*} \leq y_{S}^{*}$, and the submodularity of $\pi\left(\pi_{10}+\pi_{01} \geq \pi_{11}+\pi_{00}\right)$ is equivalent to $1 \geq \frac{\pi_{11}-\pi_{01}}{\pi_{10}-\pi_{00}}$, or $y_{L}^{*} \leq y_{F}^{*}$.
} 


\subsection{R\&D Investment with Spillovers}

It is natural to construe investment expenditures as investments in R\&D. In fact, it is these applications that the timing games literature - upon which real option games are built - considered originally (Reinganum [25]). In this application we specify the reduced form flow profits by adapting an approach to R\&D due to Kamien, Muller, and Zang [19]. ${ }^{25}$

Two firms engage in R\&D before selling vertically differentiated products. Each firm's decides on an amount of R\&D expenditure, denoted by $x_{i}, i \in\{1,2\}$, which is taken here to be a discrete choice in $\{0, \bar{x}\}$. To be consistent with the assumption of a multiplicative shock, we suppose that R\&D is demand-enhancing, i.e. firm $i$ 's inverse demand function is linear and specified as $p_{i}=a+\sqrt{\frac{2}{\gamma}\left(x_{i}+\theta x_{j}\right)}-q$, where $p_{i}$ is firm $i$ 's price, $q$ the total quantity, and the variable cost of production is zero. In such models of $R \& D$, the parameter $\theta \in[0,1]$ reflects the degree of inter-firm technological spillovers. ${ }^{26}$ If $\theta=0$, each firm's individual R\&D expenditure benefits only itself. If $\theta=1$, the benefit spills over completely to the other firm. With these assumptions, it can be verified that, up to a normalization, gross instantaneous profits are $\pi_{00}=a^{2}, \pi_{10}=(a+\sqrt{x}(2-\sqrt{\theta}))^{2}, \pi_{01}=(a+\sqrt{x}(2 \sqrt{\theta}-1))^{2}$, and $\pi_{11}=(a+\sqrt{x} \sqrt{1+\theta})^{2}$, so investment is always jointly desirable $\left(\pi_{00} \leq \pi_{11}\right)$, and $\pi$ is submodular. ${ }^{27}$ Here $x$ is an R\&D budget. Therefore, we specify the cost of exercising the investment option as $I_{L}=I_{F}=x$. In the simultaneous case, we specify $I_{S}=(1+\rho) x$. The latter parametrization reflects a possible pecuniary synergy $(-1<\rho \leq 0)$ or congestion $(\rho>0)$ when firms conduct R\&D simultaneously (see Vencatachellum and Versaevel [28] and references therein).

In this example, as $\zeta_{F}=1$ (by assumption), Proposition 1-(i) never applies. We also have $\zeta_{F} \geq \zeta_{P}$ (because $\zeta_{P} \in(0,1]$ from Lemma 1 ), and $\pi_{11}<\pi_{10}$ (negative profit externalities) if and only if $\theta<9 / 16$ (i.e., spillovers are low enough). It follows that, in the latter case, Proposition 1-(ii) applies, so that a preemption equilibrium exists, otherwise the game is one of attrition.

Joint investment is always desirable $\left(\pi_{00}<\pi_{11}\right)$, so in a simultaneous equilibrium, both firms engage in $\mathrm{R} \& \mathrm{D}$ at the finite trigger $y_{S}^{*}$. It is also easy to check that, in the low-spillover case, nonpositive profit externalities imply that Assumption $(A)$ holds for all $\beta$, and $y_{L}^{*}<y_{F}^{*}$ so Assumption

\footnotetext{
${ }^{25}$ The R\&D specifications that we use here results in submodular profits over the relevant parameter range, which simplifies the analysis. This does not hold with R\&D outputs as in d'Aspremont and Jacquemin [8]'s model (in lieu of R\&D inputs as in Kamien et al. [19]), which researchers have argued possesses less intuitive properties (Amir $[1])$.

${ }^{26}$ Spillovers are usually denoted by the letter $\beta$, but we use $\theta$ here to avoid confusion with the discounting parameter.

${ }^{27}$ Rearranging, one finds $\pi_{00}+\pi_{11}-\pi_{10}-\pi_{01}=-2(1+\sqrt{\theta}-\sqrt{1+\theta})\left(a+\frac{2(\sqrt{\theta}-1)^{2} \sqrt{x}}{1+\sqrt{\theta}-\sqrt{1+\theta}}\right) \sqrt{x}<0$, all $x>0$.
} 
$(B)$ holds also whenever $y_{L}^{*}<y_{S}^{*}$, or equivalently $\rho \geq-\frac{\pi_{10}-\pi_{11}}{\pi_{10}-\pi_{00}}$. In that case Proposition 2 applies, and we need only concentrate on condition (7) for the existence of a simultaneous (coordination) equilibrium. If $\rho<-\frac{\pi_{10}-\pi_{11}}{\pi_{10}-\pi_{00}}$, recall that (7) remains sufficient for a simultaneous equilibrium. Finally, (7) holds for $\beta=1$, so the existence of simultaneous equilibrium is thus established for $\beta$ in a neighborhood of 1 when the derivative of the left-hand term is strictly positive.

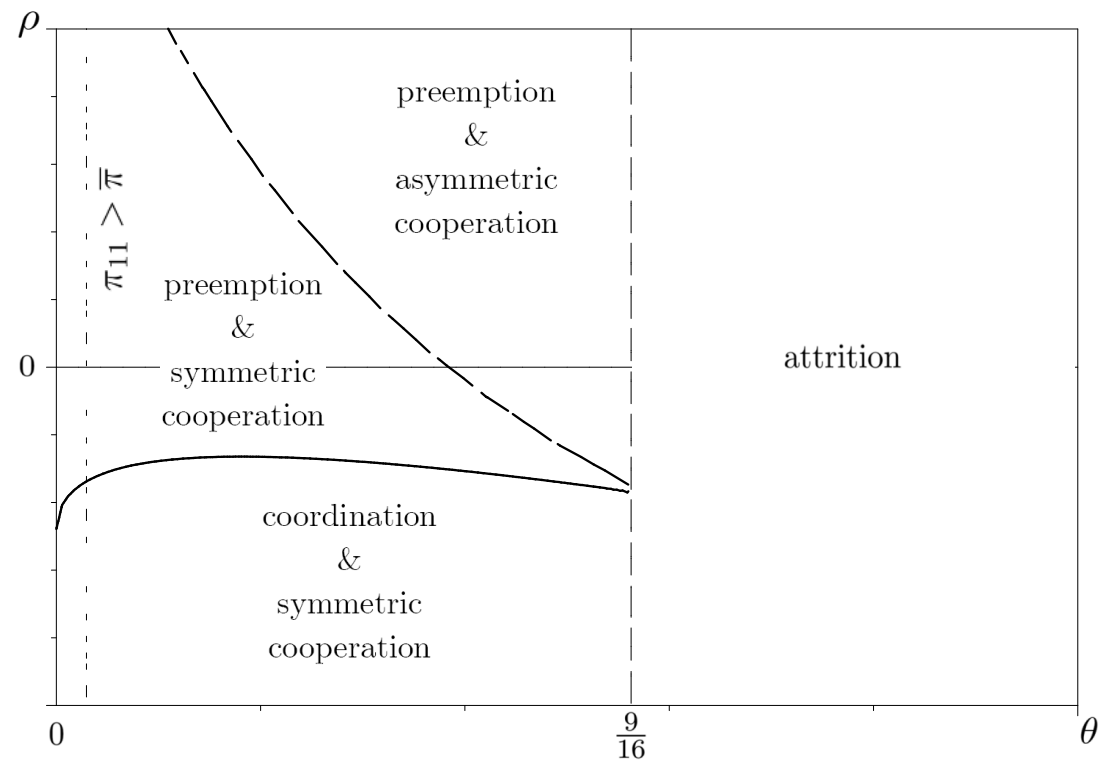

Figure 3: Simultaneous coordination equilibrium (solid curve) and cooperation regions (dashed curve) with linear demand and R\&D input choice, given profit spillovers $(\theta)$ and investment externality parameter $(\rho)$.

The latter result may be represented in the parameter space $(\theta, \rho)$. In Figure 3 , to the left of the dashed line $\left(\theta=\frac{9}{16}\right)$, firms play a game of preemption rather than attrition, and the solid curve delimits the region over which a simultaneous equilibrium exists. When profit externalities are not too large $\left(\theta \leq \frac{9}{16}\right)$ and there are synergies resulting from simultaneous investment $(\rho$ negative and low enough), then a simultaneous equilibrium exists for a low enough discounting $\operatorname{term} \beta$.

A key area of interest in models of $R \& D$ is the study of inter-firm (horizontal) cooperation. This reflects both firm practice, and the fact that $R \& D$ cooperation agreements are accepted, if not viewed favorably, by competition authorities (Martin [19]). Since firms may legally make 
binding agreements in this context, the cooperation framework (Proposition 5) seems to be the most adapted. An important result from the literature using static games is that industry profit in not necessarily quasiconcave, so a corner solution with asymmetric investment can be optimal in the cooperative regime, one firm then relying on the R\&D effort of the other (Leahy and Neary, $[21])$.

To apply Proposition 5, it is first useful to observe that as $\boldsymbol{\pi}$ is strictly submodular $\left(\pi_{00}+\pi_{11}<\right.$ $\left.\pi_{10}+\pi_{01}\right)$ we have $\zeta_{F}=1>\frac{\pi_{11}-\bar{\pi}}{\bar{\pi}-\pi_{00}}$, so the industry payoff $(J)$ has a well-defined maximum. The submodularity of $\boldsymbol{\pi}$, together with joint investment desirability, also directly imply that monopoly investment raises industry profit $\left(\pi_{00}<\bar{\pi}\right)$. It follows that case $(i i)$ in Proposition 5 determines the $\mathrm{R} \& \mathrm{D}$ choice under a cooperative regime. Whether investment triggers are symmetric or not then depends on condition (13).

In Figure 3, to the right of the dotted line we have $\pi_{11}>\bar{\pi}$, although the distinction is not important with the parameter values that are adopted here. The dashed curve is the locus of points at which condition (13) just holds, assuming $\beta=2$. Thus, for large enough externalities, asymmetric duopoly investment is optimal. Moreover, symmetric investment may be optimal, but nevertheless not arise as a non-cooperative equilibrium. Below the solid curve, the simultaneous equilibrium coincides with the industry optimum.

To summarize, from the specification of investment cost externalities, together with conditions (7) and (13), in this example we have:

Proposition 7 The greater the synergy (the smaller is $\rho$ ), the more likely the existence of a simultaneous (coordination) equilibrium, and the more likely it is that optimal cooperation and the simultaneous (coordination) equilibrium coincide.

\section{References}

[1] Amir, R., 2000. "Modelling Imperfectly Appropriable R\&D via Spillovers", International Journal of Industrial Organization, Vol. 18, No. 7, pp. 1013-1032.

[2] Azevedo, A., and Paxson, D., 2011. "Developing Real Option Game Models", working paper.

[3] Billette de Villemeur, E., Ruble, R., and Versaevel, B., 2011. "On the Timing of Vertical Relations", working paper. 
[4] Boyer, M., Lasserre, P., and Moreaux, M., 2011. "A Dynamic Duopoly Investment Game without Commitment under Uncertain Market Expansion", working paper.

[5] Boyer, M., Gravel, E., and P. Lasserre, 2011. "Real Options and Strategic Competition: A Survey", CIRANO working paper, forthcoming.

[6] Chevalier-Roignant, B., and Trigeorgis, L., 2011. Competitive Strategy: Options and Games, MIT Press.

[7] Chevalier-Roignant, B., Flath, C., Huchzermeier, A., and Trigeorgis, L., 2010. "Strategic investment under uncertainty: a synthesis", SSRN working paper.

[8] d'Aspremont, C. and Jacquemin, A., 1988. "Cooperative and Non-Cooperative R\&D in Duopoly with Spillovers", American Economic Review, Vol. 78, No. 5, pp. 1133-1137.

[9] Dixit, A., and Pindyck, R., 1994. Investment under Uncertainty, Princeton.

[10] Friedman, J., 1971. "A non-cooperative equilibrium for supergames", Review of Economic Studies, Vol. 38, No. 1, pp. 1-12.

[11] Fudenberg, D., and Tirole, J., 1985. "Preemption and Rent Equalization in the Adoption of New Technology", Review of Economic Studies, Vol. 52, No. 3, pp. 383-401.

[12] Grenadier, S., 1996. "The Strategic Exercise of Options: Development Cascades and Overbuilding in Real Estate Markets", Journal of Finance, Vol. 51, No. 5, pp. 1653-1679.

[13] Grenadier, S. and Wang, N., 2005. "Investment Timing, Agency, and Information", Journal of Financial Economics, Vol. 75, No. 3, pp. 493-533.

[14] Hoppe, H., 2000. "Second-Mover Advantages in the Strategic Adoption of a New Technology under Uncertainty", International Journal of Industrial Organization, Vol. 18, No. 2, pp. 315-338.

[15] Huisman, K., 2010. Technology Investment: A Game-Theoretic Real Options Approach, Kluwer.

[16] Huisman, K. and Kort, P., 1999. "Effects of Strategic Interactions on the Option Value of Waiting", working paper.

[17] Huisman, K., Kort, P., and Thijssen, J., 2002, "Symmetric Equilibrium Strategies in Game Theoretic Real Option Models", working paper. 
[18] Huisman, K., Kort, P., and Thijssen, J., 2006. "The Effects of Information on Strategic Investment and Welfare", Economic Theory, Vol. 28, No. 2, pp. 399-424.

[19] Kamien, M., Muller, E. and Zang, I., 1992. "Research Joint Ventures and R\&D Cartels", American Economic Review, Vol. 82, No. 5, pp. 1293-1306.

[20] Kort, P., and Pawlina, G., 2006. "Real Options in an Asymmetric Duopoly: Who Benefits from Your Competitive Disadvantage?", Journal of Economics 8 Management Strategy, Vol. 15, No. 1, pp. 1-35.

[21] Leahy, D., and Neary, J., 2005. "Symmetric Research Joint Ventures: Cooperative Substitutes and Complements", International Journal of Industrial Organization, Vol. 23, No. 5-6, pp. 381-397.

[22] Li, Y., and Sick, G., 2011. "Investment under Uncertainty: an Equilibrium between Competition and Cooperation", working paper.

[23] Martin, S., 1996. "Public policies towards cooperation in research and development: The European Union, Japan and the United States." In Competition Policy in the Global Economy, ed. Leonard Waverman, William S. Comanor, and Akira Goto (London: Routledge) chapter 10.

[24] Mason, R., and Weeds, H., 2009. "Investment, Uncertainty, and Preemption", International Journal of Industrial Organization, Vol. 28, No. 3, pp. 278-287.

[25] Reinganum, J., 1981. "On the Diffusion of a New Technology: A Game Theoretic Approach", Review of Economic Studies, Vol. 48, No. 3, pp. 395-405.

[26] Smets, F., 1991. "Exporting versus FDI: The Effect of Uncertainty, Irreversibilities, and Strategic Interactions", working paper.

[27] Smit, H., and Trigeorgis, L., 2004. Strategic Investment: Real Options and Games, Princeton.

[28] Vencatachellum, D., and Versaevel, B., 2009. "R\&D Delegation in a Duopoly with Spillovers", The B.E. Journal of Economic Analysis 8 Policy (contributions), Vol. 9, No. 1, Article 55.

[29] Weeds, H., 2002. "Strategic Delay in a Real Options Model of R\&D Competition", Review of Economic Studies, Vol. 69, No. 3, pp. 729-747. 


\section{A Appendix}

\section{A.1 Proof of Lemma 1}

Let $z \equiv \frac{\pi_{11}-\pi_{01}}{\pi_{10}-\pi_{01}} \in(0,1)$, so $\zeta_{P}(z, \beta)=\left(\beta z^{\beta-1}-(\beta-1) z^{\beta}\right)^{\frac{1}{\beta-1}}$ is well-defined. Then $\frac{\partial \zeta_{P}}{\partial z}(z, \beta)=$ $\beta z^{\beta-2}(1-z)\left(\beta z^{\beta-1}-(\beta-1) z^{\beta}\right)^{\frac{2-\beta}{\beta-1}}>0$.

Since $\zeta_{P}(0, \beta)=0$ and $\zeta_{P}(1, \beta)=1$, it follows that $\zeta_{P}(z, \beta) \in(0,1)$.

Also, $\frac{\partial \zeta_{P}}{\partial \beta}(z, \beta)=\frac{1}{\beta-1}\left[\frac{1-z}{\beta-(\beta-1) z}-\frac{\ln (\beta-(\beta-1) z)}{\beta-1}\right] \zeta_{P}(z, \beta)$. Since $x \ln x \geq x-1$ with equality if and only if $x=1,(\beta-(\beta-1) z) \ln (\beta-(\beta-1) z)>(\beta-1)(1-z)$ so $\frac{\partial \zeta_{P}}{\partial \beta}(z, \beta)<0$.

\section{A.2 Proof of Proposition 1}

The existence of a preemption equilibrium hinges on the behavior of the difference $L(y)-F^{*}(y)$. Since $L(0)-F^{*}(0)=-I_{L}<0$, preemption occurs if and only if there exists a $y$ in $\left(0, y_{F}^{*}\right)$ such that this difference is non-negative. Let $f(y) \equiv L(y)-F^{*}(y)$ so

$$
f(y)=\frac{\pi_{10}-\pi_{01}}{r-\alpha} y-I_{L}-\left(\frac{y}{y_{F}^{*}}\right)^{\beta} \frac{I_{F}}{\beta-1} \frac{\beta\left(\pi_{10}-\pi_{11}\right)+\left(\pi_{11}-\pi_{01}\right)}{\pi_{11}-\pi_{01}}, \text { all } y \leq y_{F}^{*} .
$$

Then the preemption threshold $y_{P}$ is the lower root of the equation $f(y)=0$ in $\left(0, y_{F}^{*}\right)$, if it exists. There are two cases to consider.

(i) $\pi_{11} \geq \pi_{10}$

There are two subcases to consider. First, if $\pi_{11}-\pi_{01}>\beta\left(\pi_{11}-\pi_{10}\right)$, then $f(y)$ is strictly concave in $y$, and $f^{\prime}(\widehat{y})=0$ for

$$
\widehat{y}=\left[\frac{\pi_{10}-\pi_{01}}{\beta \pi_{10}-(\beta-1) \pi_{11}-\pi_{01}}\right]^{\frac{1}{\beta-1}} y_{F}^{*} .
$$

The maximizer satisfies $\widehat{y} \geq y_{F}^{*}$. Otherwise, if $\pi_{11}-\pi_{01} \leq \beta\left(\pi_{11}-\pi_{10}\right)$, then $f(y)$ is increasing and strictly convex in $y$. In both of these subcases, $f(y)$ is increasing in $y$ over the relevant interval $\left(0, y_{F}^{*}\right)$, and therefore a preemption equilibrium exists if and only if $f\left(y_{F}^{*}\right)=I_{F}-I_{L}>0$, i.e. if $\zeta_{F}>1$.

(ii) $\pi_{11}<\pi_{10}$

In this case, $\pi_{11}-\pi_{01} \geq 0>\beta\left(\pi_{11}-\pi_{10}\right)$, so $f(y)$ is strictly concave in $y$, with a maximum at $\widehat{y}$. Moreover, the maximizer satisfies $\widehat{y}<y_{F}^{*}$. Therefore, a preemption equilibrium exists if and only if $f(\widehat{y})>0$. Evaluating and simplifying yields that $f(\widehat{y})>0$ if and only if $\zeta_{F} \geq \zeta_{P}$. To establish this, insert the developed expressions of $y_{F}^{*}$ and $\widehat{y}$ in (14), and the inequality follows by rearranging. 


\section{A.3 Proof of Proposition 2}

A simultaneous equilibrium exists whenever $y_{i}=y_{S}^{*}$ is a best response to $y_{-i}=y_{S}^{*}$, that is whenever $S^{*}(y) \geq L(y)$ for $y \in\left[0, y_{S}^{*}\right]$. The function $S^{*}(y)-L(y)$ is continuous and differentiable with $S^{*}(y)-L(y) \equiv \widehat{f}(y)$, for $y \in\left[0, \min \left\{y_{F}^{*}, y_{S}^{*}\right\}\right)$. Note that $\widehat{f}^{\prime}(0)=-\frac{\pi_{10}-\pi_{00}}{r-\alpha}$, and $\widehat{f}^{\prime \prime}(y)=$ $\beta I_{S} \frac{y^{\beta-2}}{y_{S}^{* \beta}}+\beta(\beta-1) \frac{\pi_{10}-\pi_{11}}{r-\alpha} \frac{y^{\beta-2}}{y_{F}^{* \beta-1}}$. The function $\widehat{f}$ is convex (Assumption $\left.(A)\right)$ if and only if $\frac{\pi_{11}-\pi_{00}}{y_{S}^{* \beta-1}}+\beta \frac{\pi_{10}-\pi_{11}}{y_{F}^{* \beta-1}}>0$, in which case $\widehat{f}$ has a well-defined global minimum in $\mathbb{R}_{+}$, that we denote by $\widehat{y}$, defined by the condition:

$$
\frac{\pi_{10}-\pi_{00}}{\widehat{y}^{\beta-1}}=\frac{\pi_{11}-\pi_{00}}{y_{S}^{* \beta-1}}+\beta \frac{\pi_{10}-\pi_{11}}{y_{F}^{* \beta-1}} .
$$

When $\widehat{f}$ is convex, a non-negative minimum is sufficient to establish existence of a simultaneous equilibrium $(\Rightarrow)$. Moreover, after rearrangement, $\widehat{f}(\widehat{y})=\left(1-\frac{\widehat{y}}{y_{L}^{*}}\right) I_{L}$, so $\widehat{f}(\widehat{y}) \geq 0$ if and only if $\widehat{y} \leq y_{L}^{*}$, which again after some rearrangement occurs is equivalent to the condition in (7).

Necessity $(\Leftarrow)$ remains to be established. If $\widehat{y}<\min \left\{y_{F}^{*}, y_{S}^{*}\right\}$, with convexity (Assumption $(A)), \widehat{f}(\widehat{y}) \geq 0$ (that is, (7)) is necessary for the existence of a simultaneous (coordination) equilibrium. Otherwise, we proceed by distinguishing two cases.

Case 1: $y_{S}^{*} \leq y_{F}^{*}$

If $y_{S}^{*} \leq y_{F}^{*}$, then $S^{*}(y)-L(y) \geq 0$ on $\left[0, y_{S}^{*}\right]$ if and only if $\min _{\left[0, y_{S}^{*}\right]} \widehat{f}(y) \geq 0$. For $y_{S}^{*} \leq \widehat{y}$, we have

$$
\widehat{f}\left(y_{S}^{*}\right)=\left[1+\frac{\beta}{\beta-1} \frac{y_{S}^{*}}{y_{L}^{*}}\left(\frac{1}{\beta}\left(\frac{y_{S}^{*}}{\widehat{y}}\right)^{\beta-1}-1\right)\right] I_{L} \leq\left(1-\frac{y_{S}^{*}}{y_{L}^{*}}\right) I_{L} \leq 0 .
$$

The last inequality follows from Assumption $(B)$. Therefore, in this case $S^{*}(y)-L(y) \geq 0$ on $\left[0, y_{S}^{*}\right]$ if and only if $\widehat{f}(\widehat{y}) \geq 0$.

Case 2: $y_{S}^{*} \geq y_{F}^{*}$

If $y_{S}^{*} \geq y_{F}^{*}$, then $S^{*}(y)-L(y) \geq 0$ on $\left[0, y_{S}^{*}\right]$ if and only if $\widehat{f}(y) \geq 0$ for $y \in\left[0, y_{F}^{*}\right]$ and $S^{*}(y)-L(y)=-\frac{\pi_{11}-\pi_{00}}{r-\alpha} y+I_{S}+\left(\frac{y}{y_{S}^{*}}\right)^{\beta} \frac{I_{S}}{\beta-1} \geq 0$ for $y \in\left[y_{F}^{*}, y_{S}^{*}\right]$. Since $S^{* \prime}(y)-L^{\prime}(y) \leq$ 0 for $y \in\left[y_{F}^{*}, y_{S}^{*}\right]$ with $S^{*}\left(y_{S}^{*}\right)-L\left(y_{S}^{*}\right)=0$, this second inequality always holds. Therefore, $S^{*}(y)-L(y) \geq 0$ on $\left[0, y_{S}^{*}\right]$ if and only if $\min _{\left[0, y_{F}^{*}\right]} \widehat{f}(y) \geq 0$. For $y_{F}^{*} \leq \widehat{y}$, by (16) we have $\left(\frac{y_{F}^{*}}{y_{S}^{*}}\right)^{\beta} \leq \frac{-(\beta-1) \pi_{10}+\beta \pi_{11}-\pi_{00}}{\pi_{11}-\pi_{00}} \frac{I_{F}}{I_{S}}$. Then,

$$
\widehat{f}\left(y_{F}^{*}\right)=-\frac{\pi_{11}-\pi_{00}}{r-\alpha} y_{F}^{*}+I_{L}+\left(\frac{y_{F}^{*}}{y_{S}^{*}}\right)^{\beta} \frac{I_{S}}{\beta-1} \leq\left(1-\frac{y_{F}^{*}}{y_{L}^{*}}\right) I_{L} \leq 0 .
$$


The last inequality follows from Assumption $(B)$. Therefore, in this case $S^{*}(y)-L(y) \geq 0$ on $\left[0, y_{S}^{*}\right]$ if and only if $\widehat{f}(\widehat{y}) \geq 0$.

Combining both cases, $S^{*}(y)-L(y) \geq 0$ on $\left[0, y_{S}^{*}\right]$ if and only if $\widehat{f}(\widehat{y}) \geq 0$, that is if and only if (7) holds.

\section{A.4 Proof of Proposition 3}

Proceed by contradiction, by supposing that $V_{P}(y)>S^{*}(y)$ for some $y \in\left[0, y_{S}^{*}\right]$. Then

$$
\left(\frac{y}{y_{P}}\right)^{\beta}\left[L\left(y_{P}\right)-\frac{\pi_{00}}{r-\alpha} y_{P}\right]>\frac{I_{S}}{\beta-1}\left(\frac{y}{y_{S}^{*}}\right)^{\beta} \text {. }
$$

Since Assumption $(A)$ holds, $\widehat{y}$ is well-defined (by (16)), and if $y_{S}^{*}$ is a simultaneous equilibrium and Assumption $(B)$ holds, $\widehat{y} \leq y_{L}^{*}$ so

$$
\frac{I_{S}}{y_{S}^{* \beta}} \geq \frac{I_{L}}{y_{L}^{* \beta}}-\beta \frac{\pi_{10}-\pi_{11}}{\pi_{11}-\pi_{01}} \frac{I_{F}}{y_{F}^{* \beta}} .
$$

Developing $L\left(y_{P}\right)$ and using (20), (19) holds if and only if

$$
f\left(\frac{y_{P}}{y_{L}^{*}}\right) \equiv-\left(\frac{y_{P}}{y_{L}^{*}}\right)^{\beta}+\beta \frac{y_{P}}{y_{L}^{*}}-(\beta-1)>0
$$

but $f$ attains a maximum at $\frac{y_{P}}{y_{L}^{*}}=1$, with $f(1)=0$, so that $(21)$ never holds.

\section{A.5 Proof of Lemma 2}

First, let $\check{f}(\boldsymbol{\pi}, \beta) \equiv\left(\frac{\zeta_{P}}{\zeta_{S_{\infty}}(\boldsymbol{\pi}, \beta)}\right)^{\beta-1}=\left(1+\frac{1}{\beta} \frac{\pi_{11}-\pi_{01}}{\pi_{10}-\pi_{11}}\right)\left(\frac{\pi_{10}-\pi_{00}}{\pi_{10}-\pi_{01}}\right)^{\beta}$. Then, $\check{f}(\boldsymbol{\pi}, 1)=\frac{\pi_{10}-\pi_{00}}{\pi_{10}-\pi_{11}} \leq 1$, with an equality sign if and only if $\pi_{00}=\pi_{11}$, and

$$
\frac{\partial \check{f}(\boldsymbol{\pi}, \beta)}{\partial \beta}=\left[\left(1+\frac{1}{\beta} \frac{\pi_{11}-\pi_{01}}{\pi_{10}-\pi_{11}}\right) \ln \frac{\pi_{10}-\pi_{00}}{\pi_{10}-\pi_{01}}-\frac{1}{\beta^{2}} \frac{\pi_{11}-\pi_{01}}{\pi_{10}-\pi_{11}}\right]\left(\frac{\pi_{10}-\pi_{00}}{\pi_{10}-\pi_{01}}\right)^{\beta}
$$

which is negative since $\ln \frac{\pi_{10}-\pi_{00}}{\pi_{10}-\pi_{01}}<0$. Therefore, $\zeta_{P}<\zeta_{S_{\infty}}(\boldsymbol{\pi}, \beta)$. Second, $\lim _{\beta \rightarrow 1}\left(\beta \frac{\pi_{10}-\pi_{11}}{\pi_{10}-\pi_{00}}\right)^{\frac{1}{\beta-1}}=$ $\operatorname{elim}_{\beta \rightarrow 1}\left(\frac{\pi_{10}-\pi_{11}}{\pi_{10}-\pi_{00}}\right)^{\frac{1}{\beta-1}}=\infty(=\mathrm{e})$ when $\pi_{00}>\pi_{11}\left(=\pi_{11}\right)$, and $\lim _{\beta \rightarrow \infty}\left(\beta \frac{\pi_{10}-\pi_{11}}{\pi_{10}-\pi_{00}}\right)^{\frac{1}{\beta-1}}=1$, so $\zeta_{S_{\infty}}(\boldsymbol{\pi}, \beta) \in\left[\frac{\pi_{11}-\pi_{01}}{\pi_{10}-\pi_{00}}, \infty\right)$. Also

$$
\frac{\partial \zeta_{S_{\infty}}(\boldsymbol{\pi}, \beta)}{\partial \beta}=\frac{1}{(\beta-1)^{2}}\left[\frac{\beta-1}{\beta}-\left(\ln \beta+\ln \frac{\pi_{10}-\pi_{11}}{\pi_{10}-\pi_{00}}\right)\right] \zeta_{S_{\infty}}(\boldsymbol{\pi}, \beta) .
$$

The expression in brackets is negative since $\frac{\pi_{10}-\pi_{11}}{\pi_{10}-\pi_{00}} \geq 1$ and $\beta \ln \beta>\beta-1$ (recall that $\beta>1$ ), so $\frac{\partial \zeta_{S \infty}(\boldsymbol{\pi}, \beta)}{\partial \beta}<0$. 


\section{A.6 Proof of Proposition 4}

A simultaneous "non-investment" equilibrium exists if and only if $y_{i}=y_{S}^{*}(=\infty)$ is a best-response to $y_{-i}=y_{S}^{*}$, that is if $S^{*}(y) \geq L(y)$ over the interval $\left[0, y_{F}^{*}\right]$. Note that here, the simultaneous investment payoff has the simple form $S^{*}(y)=\frac{\pi_{00}}{r-\alpha} y$. Let $\widehat{f}(y) \equiv S^{*}(y)-L(y)$ (see proof of Proposition 2), then $S^{*}(y) \geq L(y)$ over the interval $\left[0, y_{F}^{*}\right]$ if and only if $\min _{\left[0, y_{F}^{*}\right]} \widehat{f}(y)=\widehat{f}(\widehat{y}) \geq 0$ which occurs if and only if $\beta\left(\frac{y_{F}^{*}}{y^{*}}-\zeta_{F}\right)\left(\frac{y_{L}^{*}}{y_{F}^{*}}\right)^{\beta} \geq 1$ (i.e., $\left.\zeta_{F} \leq \zeta_{S_{\infty}}\right)$.

\section{A.7 Proof of Proposition 5}

If $\bar{\pi} \leq \pi_{00}, J$ is increasing in $y_{L}$ over $\mathbb{R}_{+}$and the optimum is $\left(y_{S}^{*}, y_{S}^{*}\right)$ on the boundary of $J$ 's domain. Note that when $\pi_{00} \geq \pi_{11}, y_{S}^{*}=\infty$. If $\pi>\pi_{00}, J$ is quasiconcave in $y_{L}$ with an interior optimum at $y_{L}^{* *}$. If $\bar{\pi} \geq \pi_{11}, J$ is increasing in $y_{F}$ over over $\mathbb{R}_{+}$and the global optimum is $\left(y_{L}^{* *}, \infty\right)$, i.e. monopoly investment. Otherwise $\left(\bar{\pi} \in\left(\pi_{00}, \pi_{11}\right)\right)$, the optimal second trigger is finite, $y_{F}^{* *}$. Note that $y_{F}^{* *}>y_{L}^{* *}$ if $\zeta_{F}>\frac{\pi_{11}-\bar{\pi}}{\bar{\pi}-\pi_{00}}$. The condition (13) assures that the local maximum $\left(y_{L}^{* *}, y_{F}^{* *}\right)$ is a strict global maximum. Finally, this condition always holds if $\pi_{11} \leq \pi_{00}$.

\section{A.8 Proof of Lemma 3}

For the first part, evaluating in the case where $\pi_{11} \geq \pi_{00}$ (otherwise $w$ can be set to 0 ),

$$
\tilde{f}^{\prime \prime}(\beta)=\left(\widetilde{f}^{\prime}(\beta)-w^{\beta} \ln w\right) \ln v+u v^{\beta} \ln v+w^{\beta}(\ln w)^{2},
$$

so at any $\beta_{0}$ satisfying $\widetilde{f}^{\prime}\left(\beta_{0}\right)=0$,

$$
\tilde{f}^{\prime \prime}\left(\beta_{0}\right) \leq w^{\beta_{0}}(\ln w)(\ln w-\ln v) \leq 0,
$$

where the first inequality holds because $\ln v \leq 0$, and the second because $w \leq v$. For the second part, $\tilde{f}(1)=\frac{\pi_{10}-\pi_{11}}{\pi_{10}-\pi_{00}}+\mathbf{1}_{\pi_{11}>\pi_{00}} \frac{\pi_{11}-\pi_{00}}{\pi_{10}-\pi_{00}}$. If $\pi_{11}<(=) \pi_{00}$ we have $\tilde{f}(1)=\frac{\pi_{10}-\pi_{11}}{\pi_{10}-\pi_{00}}>(=) 1$, otherwise $\tilde{f}(1)=1$. 